\title{
Family Caregivers' Perspective on Factors Affecting Recovery from Schizophrenia
}

\author{
S Gandhi, D Jones
}

\begin{abstract}
Objective: To explore caregivers' perspective on factors affecting the recovery of their family members diagnosed with schizophrenia.

Methods: A qualitative grounded theory approach was used. A convenience sample of seven male and eleven female family caregivers of patients with schizophrenia were invited from outpatient $(n=6)$, inpatient $(n=7)$, and psychiatric rehabilitation $(n=5)$ services in an Indian mental health institute to participate in semi-structured interviews. Interviews were recorded, transcribed, and analysed. Similar themes were grouped and the main themes identified.

Results: Caregivers' perspectives on factors affecting recovery from schizophrenia were categorised to two themes: facilitators and barriers. The nine facilitators were (1) getting into a precise treatment regimen and sticking to it, (2) developing some personal attributes, (3) exercising family's role diametrically, (4) paying attention to basic needs, (5) sharing with the Almighty, (6) adapting to a supportive lifestyle, (7) not being idle... engage in something, (8) coming out, being and sharing with others, and (9) having adequate resources with a good support system. The ten barriers were (1) detrimental treatment practices, (2) hampering illness impacts, (3) off-putting personality elements, (4) unaccommodating family circumstances, (5) caregivers' limitation, (6) flaccid support system and scarce resources, (7) ambiguous treatment outcome or prognosis, (8) futile religious, health, and social belief systems, (9) situational factors, and (10) presence of troubling physical or psychological stressors.

Conclusion: The recovery process is facilitated through family involvement and support by mental health professionals. Thus, giving a pre-treatment counselling to the caregivers and repeating the same content to the patients after regaining insight can be helpful.
\end{abstract}

Key words: Caregivers; Grounded theory; Mental health recovery; Schizophrenia

Sailaxmi Gandhi, Department of Nursing, National Institute of Mental Health and Neurosciences (NIMHANS) - An Institute of National Importance, Bengaluru, Karnataka, India

Diksy Jones, Department of Nursing, Government Mental Health Centre, Thrissur, Kerala, India

Address for correspondence: Dr Sailaxmi Gandhi, Department of Nursing, ASHWINI Block, National Institute of Mental Health \& Neurosciences (NIMHANS) - An Institute of National Importance, Hosur Road, Bengaluru 560029, Karnataka, India.

Email: sailaxmi63@yahoo.com

Submitted: 17 June 2019; Accepted: 14 April 2020

\section{Introduction}

With improved medications and treatment, more patients with mental illness can be treated in an outpatient setting. ${ }^{1}$ Hence, families have more important roles in the recovery process of their members with schizophrenia. In India, $87.7 \%$ of people with schizophrenia are living in the community with their families. ${ }^{2}$ Family plays a vital role in their treatment and care. Caregivers have enormous influence on persons with schizophrenia in living a productive, integrated life in the community. ${ }^{3}$

In a study to explore viewpoints about recovery in 32 patients with schizophrenia and their caregivers, symptom control and cognitive ability are more important to persons with schizophrenia, whereas independent functioning and fulfilment of duties are more important to caregivers. ${ }^{4}$ It may be difficult to provide care according to individual goals and wishes, because family caregivers and patients have different informational and support needs, which vary depending on their familiarity with mental health services, the acuity of problems, the presence of crisis, and the context in which care takes place., Caregivers are often the lifeline to the community for those with schizophrenia. ${ }^{7}$ Thus, it is important to identify a united and multi-focal consumer perspective of factors affecting recovery while executing recovery-oriented services. Identifying caregivers' perspectives can enhance the clinical understanding of the recovery process and give family members a sense of hope about their lives and the lives of their family members with disability. ${ }^{8}$

\section{Methods}

This study used a qualitative grounded theory approach. A convenience sample of seven male and eleven female family caregivers of persons diagnosed with schizophrenia according to the ICD 10 (F20) criteria and treated for $\geq 1$ year was invited to participate in semi-structured interviews. They were recruited from outpatient $(n=6)$, inpatient $(\mathrm{n}=7)$, and psychiatric rehabilitation $(\mathrm{n}=5)$ 
services of the National Institute of Mental Health and Neuro Sciences in India (Table 1). Caregivers who were receiving treatment for chronic physical or mental illness were excluded.

Theoretical sampling was used for the construct of different categories of sociodemographic and illness backgrounds. Theoretical sampling permits refinement and saturation of developed categories. Sampling was continued until data saturation. The research instruments used were topic guides, subjective observations, and reflective notes. The topic guides were "What helps your family member in recovering from the illness? I would like to know more about this." and "What are the factors which prevent or obstruct your family member's recovery? I would like to know more about this." Probes and suggestions were used to elicit more detailed information. Further decisions were made based on the results of the analysis of each interview, as to what data and from whom data should be collected.

After obtaining approval from the ethics committee and informed consent from each participant, each caregiver was interviewed for approximately 30 minutes. Interviews were audio recorded and other non-verbal cues were noted. The audio records were transcribed and translated into English.

To avoid bias, we bracketed the second author's preconceived thoughts, feelings, and beliefs; wrote reflective notes after each interview; reviewed the literature after data collection and analysis; and triangulated (environmental and theoretical) while collecting and coding the data and finally reflective discussion with experts.

Data were analysed simultaneously, and sampling continued until no new themes arose from interviews. Constant comparison was performed throughout the analysis. The analysis was carried out in four phases. In the concept formation phase, the transcribed data were read thoroughly, and open coding was performed. In the concept development phase, selective coding (or categorical coding) was performed by forming different categories with almost the same concepts. Main themes were developed from each category (theoretical coding) by detailed analysis of categories and themes with other categories and themes including reduction of themes by integrating similar themes. In the concept modification and integration phases, all themes derived from participants' narratives were reported and all memos and notes integrated.

Soundness or trustworthiness of the study was established. Credibility was established by debriefing with experts, keeping track of notes, contacting participants when required, and by environmental and theoretical triangulation. Transferability was established by purposivetheoretical sampling to maximise the range of information covered, collection of rich narrative data, along with field notes, memos, and clear description of the selection of participants. Dependability was established by providing descriptive details of methods used to gather, analyse, and

Table 1. Characteristics of participants

\begin{tabular}{|lllll|}
\hline Sex/age, & Education & $\begin{array}{l}\text { Socioeconomic } \\
\text { status }\end{array}$ & Occupation & $\begin{array}{l}\text { Relationship with } \\
\text { patient }\end{array}$ \\
M/58 & Pre-degree & Middle & Business & Husband \\
\hline M/78 & Degree & High & Retired engineer & Father \\
\hline F/52 & 9th grade & Low & Tailoring & Mother \\
\hline F/26 & Degree & Low & Accountant & Sister \\
\hline M/32 & Pre-degree & Low & Mechanic & Son \\
\hline F/76 & Nil & Low & Nil & Mother \\
\hline F/46 & 8th grade & Low & Nil & Sister \\
\hline F/55 & 3rd grade & Low & Daily wage & Mother \\
\hline F/76 & Nil & Low & Nil & Mother \\
\hline M/54 & Degree & High & Manager & Husband \\
\hline F/50 & Secondary Level School Certificate & Middle & Nil & Mother \\
\hline M/57 & Secondary Level School Certificate & Middle & Agriculture & Father \\
\hline F/65 & Nil & Low & Daily wage & Mother \\
\hline F/62 & 9th grade & Middle & Nil & Mother \\
\hline F/78 & Nil & Low & Nil & Mother \\
\hline F/46 & Degree & Middle & Teacher & Wife \\
\hline M/78 & 4th grade & Middle & Vendor & Father \\
\hline M/53 & Degree & High & Accountant. & Brother \\
\hline & & & & \\
\hline
\end{tabular}


interpret data. The authenticity of the data was clarified with experts. Confirmability was established by an audit trail of interview transcripts, reflective journaling following interviews, notes on planned activities related to data analysis, and all drafts of reports.

\section{Results}

Caregivers' perspectives on factors affecting recovery from schizophrenia were categorised to two themes: facilitators and barriers.

Recovery can be facilitated by managing the illness with a precise, collaborative, and holistic approach (Table 2).

1.Getting into a precise treatment regimen and sticking to it: Pharmacological treatment is the first and foremost important facilitator of recovery. The readiness to accept and explore new treatment options are always appreciated, but treatment adherence is an essential component. "Medicines have to continue... with the help of medicines he will recover very well...after the one month of initial treatment referred him to rehabilitation unit and I could feel the changes." (caregiver 2) "We tried naturopathy also. That helped a lot to reduce her weight and helped to correct her irregular menstrual periods." (caregiver 3)

2. Developing a number of personal attributes: work hard to achieve life goals with a positive mind. Forget the past and concentrate on the future. Time is a good healer. As the time goes on, the individual will be able to forget old painful experiences and come back to the normal state. "They have to forget old matters, instead of digging it.... Every person should have some aim in their life. We may have difficulties, but we have to overcome that." (caregiver 4) "He should come out from frustration.... Time passes. Time is a good healer." (caregiver 2)

3. Exercising family's role diametrically: Family has multiple roles to perform. It starts by accepting the person with all his/her positives and negatives. It is the responsibility of the family to administer medicines without fail, especially when the patient lacks insight. The individual should have some role in the family thereby some responsibility in his/ her life. "We could see the improvement after 2 months of treatment itself. She was reluctant to take medicines for the first three months. So we gave it by mixing with food. Later, we asked her to take the tablets alone... We asked her to show the tablets before taking; she followed it and started taking regularly.... Doctor told us that everybody including father has to talk to her, that itself is a type of treatment. We all started talking to her; father started helping her, used to wash her clothes, and well taken care off.... now he supports, there is good understanding between them, maintaining a good relationship with each other. That has made her mind free and relaxed it seems." (caregiver 5)

4. Paying attention to the basic needs: It is necessary to pay attention to basic requirements of the individual. Adequate food and fluid intake is very important to eliminate the unwanted effects of medicines. Shelter and clothing is a kind of self-security. "If there is some pension,

\section{Table 2. Facilitators of recovery from schizophrenia}

1. Getting into a precise treatment regime and sticking to it

- Treat with medicines

- Trust in the treating group and treatment adherence

- Simultaneous use of adjunct therapies

- Timely referral

- Early rehabilitation facilities

- Use of alternative systems of medicines

2. Developing some personal attributes

- Positive attitude

- Resilience

- Have aims in life

- Have discipline

- Curiosity

- Cultivate good habits

3. Exercising family's role diametrically

- Accept the individual as a person

- Mutual understanding and sharing

- Administration or supervision of drug intake

- Have a sharing and supportive life partner

- Good interpersonal relationship between members of the family

4. Paying attention to basic needs

- Maintain balanced diet

- Adequate fluid intake

- Satisfy primary needs: food, shelter, clothing, etc

5. Sharing with Almighty

- Prayer

- Visit to religious places

- Religious rituals

6. Adapting to a supportive lifestyle

- Lifestyle modification

- Physical exercises

- Yoga and meditation

7. Not being idle...engage in something

- Engage in interested activities

- Do not force to do work

- Free from thoughts about illness

8. Coming out, being and sharing with others

- Come out and interact with people

- Express thoughts and feelings

- Talk freely and behave properly

- Make group of friends

9. Having adequate resources and good support system

- Resources to get adequate information

- Good social contact and relations

- Material resources to avail and continue the best possible treatment

- Effective social support system 
a safe shelter, money to live, a job for income, adequate food, and dress to wear, everybody will recover. If we don't have these basic requirements, our tension will increase.... That is natural..." (caregiver 7)

5. Sharing with the Almighty: They had faith in God and were committing everything to Almighty. Worshipping or relying on the Almighty may have some effect on reducing stress and creating a positive mind. "I used to take him to temples and did poojas also. According to me prayer also will help." (caregiver 8) "God has to look after us........ God will take care....... With the help of God, doctors and all others he has brought to this level." (caregiver 17)

6. Adapting to a supporting lifestyle: Lifestyle modification is a part of the recovery process. Doing exercise, walking, practising yoga and meditation etc. will help the individual to come out from this illness. "She has to do exercise, regular walking,........" (caregiver 10) "She is still going for yoga classes, doing meditation and going for work also. I feel, these things have helped her to come out from the illness." (caregiver 11)

7. Not being idle...engage in something: Depending only on medicines without doing any other activities will never help. They should be active and engaged in some type of activities. It is important to consider individual preferences and interests and they should not feel like they are forced to do it. "...But without doing anything, simply taking medicines will never help.... She should be mentally active." (caregiver 7) "we are planning to turn his mind to a job. Now, he is taking work from nearby houses and doing without any complaints. Apart from this, he is fond of birds, and he has some collection of pets like love birds, doves and chicks. He is taking care of that also." (caregiver 12)

8. Coming out, being and sharing with others: The socially withdrawn nature of the illness is quite disturbing. They may have lots of worries and stressors. The individual should come out of their nest and interact with people, as well as express their feelings. It may be difficult to express everything to parents. Venting helps prevent piling up of stressors and future burnout. "He should be one among other people. He was always alone. He is quite intelligent but he was not expressing...seemed to be introvert.... He should understand and express his thoughts. I would say, please talk, feel free to talk to people, accept them as good friends. If they have to be good friends, he also should be a good friend to them. Otherwise they will not accept him." (caregiver 2) "Moreover, we know that this is a mental illness, and they may have lot of tensions. They have to tell us; if angry, that also. That helps to recover from illness." (caregiver 4)

9. Having adequate resources and good support system: Support from other caregivers during acute phases is important. Financial support from the society or government can reduce the caregiver burden to some extent. "There should be some provision for financial support. I requested to the doctor for disability certificate. Because, there are chances to stop medicines if there is any financial difficulty. If she gets the pension, she will be able to buy medicines...." (caregiver 13)

However, recovery can be challenged by impedances from various systems and subsystems of an individual's life circle along with after-effects of illness. Caregivers experienced barriers that interfere with the recovery process (Table 3).

1. Detrimental treatment practices: Treatment-related factors such as failure in early identification and appropriate treatment, non-compliance, failure in supervision are the most important challenges of recovery. "In childhood, he used to run away. He used to run away whenever we scold him. We didn't give much importance to that. Later, we came to know that it was abnormal; had to seek treatment. If we could identify at that time, the result might have been far better." (caregiver 12) "Improvement was there after one year of treatment, and he was supposed to continue it but he didn't. But, even without medicines he was doing well and so we didn't give much importance to treatment. So his condition became worse." (caregiver 14) "I used to give the medicines in her hand. Usually I will not check whether she takes or not. Even if I ask, she would scold me. Usually when the medicines get over, she would tell me and I would go, get it and give to her hand. This time, when I asked her to get the empty strips while going for follow up, she showed me full strips of tablet, not even touched it. I cannot ask; I am old and she is stronger than me" (caregiver 15)

2. Hampering illness impacts: The illness will affect their work performance and socialisation process. "she would sleep when she is alone, wouldn't do anything...... She could have cleaned her own room but she never does it. Even bathing, washing her clothes, at least that, nothing. So we felt that she will be relaxed if she goes outside to work. So I sent her to a tailoring class. But there she would say "I feel sleepy" and would sleep." (caregiver 3) "He passed his MCA- the correspondence course he did. He did it, but he had less job concentration, he cannot sit in one place for more than few minutes. He is very much worried about job." (caregiver 2)

3. Off-putting personality elements: Certain personality elements can block the recovery process. These may hamper the active treatment process or worsen the condition. "Extra activities will help, but she was not interested.... She is not a person who socialises with people." (caregiver 10) “...Unfortunately, his mother passed away... after that he was under deep frustration.... He had a feeling that his mother is the only nice person in the earth and not others. Once he tried to commit suicide also. So we took him to hospital and admitted there.... May be his inborn nature is like that and that may affect the recovery." (caregiver 2) "Main problem is lack of interest, no interest in anything." (caregiver 12)

4. Un-accommodating family circumstances: Family member's attitude towards illness and the ill person is significant in the recovery process. Annoying family circumstances are barriers to recovery. "He was overprotected by his mother." (caregiver 2) "There was lot 
Table 3. Barriers of recovery from schizophrenia

1. Detrimental treatment practices
- Unnoticed childhood problems
- Delay in seeking right treatment
- Lack of optimum dosage of medicines
- Inadequate duration for each drug trial
- Treatment non-compliance

2. Hampering illness impacts

- Sleep disturbances

- Lack of interest or amotivation

- Social withdrawal

- Cognitive impairments

- Perceived self stigma

3. Off-putting personality elements

- Introvert or with poor socialization skills

- Strong emotions

- Highly anxious

- Passive attitude and low interest

- Low frustration tolerance and poor resilience

4. Unaccommodating family circumstances

- Negative family emotional climate

- Disturbed interpersonal relationships

- Negative attitude towards the illness and poor family support

5. Caregivers' limitation

- Single caregiver

- Temporary change of caregivers

- Aged caregiver

- Gender difference

- Neglect from other family members

- Lack of well informed and authoritative care giver

6. Flaccid support system and scarce resources

- Inadequate social support

- Poor resources

- Problems with accessibility and availability of benefits

- Fiscal concerns

7. Ambiguous treatment outcome or prognosis

- Intermittent illness episodes and continuity of few symptoms even with continuous treatment

- Individual differences in the treatment, outcome and adverse effects

- Notion that it is a chronic illness

8. Futile religious, health and social belief systems

- Faith healing practices

- Religious taboos

- Social stigma

9. Situational factors

- Festival seasons or ceremonial functions

- Lunar effects

10. Presence of troubling physical or psychological stressors

- Co-morbid physical illnesses

- Co-morbid substance use

- Loss or failures in personal life

- Familial separation

- Legal issues of issues at home. There were quarrels between father and mother earlier. Nobody including my father was talking to her, father was not supportive. If there is any chance for the illness to come back, that can be only because of my father and also by missing the medicines." (caregiver 5) "In between he used to go to his sister's place. She won't take care properly, will not give medicines... they would say that, it is not required.... Nobody support him. He has that feeling." (caregiver 16)

5. Caregivers' limitation: Caregivers' concerns are also important. Though they want to involve actively in the caregiving process, they may not be able to do so. These limitations lead to expressed emotions and end up in burn out. " many proposals came for her, but she didn't agree. Now who will come? We are staying with my second daughter, for the past 7 years we are there. I have 5 sons also, but they are not giving anything for us.... Where do we go? Moreover, I am 82 years now. Can I go somewhere along with this sick daughter?" (caregiver 9) "She was becoming normal with regular medication. In between, our nephew's marriage was there, and they took her to their home. There they found her as sleeping always, they thought it is because of tablets, and they stopped medicines. All the problems restarted and took time to become normal.". (caregiver 3) "To bring a lady alone to hospital, that also in a problematic state, will be very difficult." (caregiver 5)

6. Flaccid support system and scarce resources: Without adequate support and resources, it is difficult to manage this illness. "She is feeling some distress in her mind. Has fear also. There are some issues in our family, our father died. We don't have any relatives.... She was doing quite well; but for few months, the problems were more. Though our father was a checking inspector, he couldn't save anything.... Brother passed away, he had cancer... and now we both are alone." (caregiver 7)

7. Ambiguous treatment outcome or prognosis: The persistence of problems even with medication and individual differences in treatment outcome can be a negative reinforcement leading to treatment discontinuation and relapse. "She was on medication for these many years. But even now we cannot reduce the dose or stop the medication...." (caregiver 4)

8. Futile religious, health, and social belief systems: Certain religious beliefs or practices can prolong the duration of illness by delaying the actual treatment. Taboos and fear of stigma can be another burden for the family. "When it started 6years before, people told us that she was possessed with some spirit and has to do some Poojas. So we went to " $S$ " temple to do poojas. We did religious remedies and practiced all religious rituals and gave offering to God also. Nothing could help her. After that also the problems continued.... We are not supposed to eat some food items. So we won't take the food provided from the hospital, we have to buy from outside. We don't have enough money to buy full meal, we buy one and share. But she is taking medicines and has to take adequate food. What can I do? I won't even get proper sleep." (caregiver 9) "Now she is better. But when 
doctors instructed to continue treatment; that made us too sad. We had a feeling that, we can stop this after some time; but when we heard the opposite, we felt bad. It wouldn't be a problem; but now our sister has got married and her husband enquires about the treatment from NIMHANS and also the medicines. That is the only problem." (caregiver 5)

9. Situational factors: The environmental changes and festival seasons have some impact on this illness. Symptom exacerbations or relapses can be noted during these seasons. "What I have observed is the problems will be more during the time of Amavasya (newmoon). Usually the symptoms will be more at that time." (caregiver 3) "What I could observe is, the problems would be more in some specific times; in all these years. That also 2-3 times in a year, the same time when it happened last year. One is at the time of Pooja holidays, next Onam; that means we were unable to celebrate any functions at home." (caregiver 1)

10. Presence of troubling physical or psychological stressors: Co-morbid physical illness can interfere in the recovery process. As psychiatric medicines have some effect on different systems of the body, the presence of co-morbid illnesses can worsen the existing problems. Loss, failures, separations and legal issues are additional burdens to the individual. "Apart from this she had sugar and BP problems, had to take medicines for that also. So she became too weak." (caregiver 5) "It was four years ago he started showing some irritability and disconnected thoughts. This started because he flopped in his business.... He had invested money in two firms and both failed. This led to issues with his wife.... He became normal after treatment.... His wife filed a case against him to get his property.... He failed in the discussions for possibilities of negotiations and settlement. So he became tensed and those problems re-started." (caregiver 14)

\section{Discussion}

Caregivers are important because they assist patients in all activities: physical, financial, and material. ${ }^{9}$ Themes identified were categorised into facilitators and barriers of recovery. The main facilitators identified were early illness identification, medication compliance, spiritual comfort, and family support. Early identification of the illness and appropriate treatment is most important. Failure to do so will hamper the recovery process. Failure to detect early or increased duration of untreated illness is a poor predictor of remission and recovery. ${ }^{10,11}$ Medication compliance is most important for the remission of symptoms and recovery. ${ }^{12}$ Poor medication compliance is associated with poor treatment response and treatment discontinuation. ${ }^{12}$ Nonadherence is associated with adverse consequences such as a higher probability of hospitalisation and higher medical costs. $^{13}$

Facilitators such as empowerment, optimism, positive self-esteem, better pre-morbid adjustment, resilience, and self-determination have been reported..$^{12,14-17}$ Support and reciprocity with family members are important dimensions of a personal support network for recovery. The positive effect of spirituality in recovery has also been reported. ${ }^{18,19}$

Major barriers perceived by caregivers were treatment non-adherence, non-therapeutic family emotional climate, caregiver burden, physical health or psychological stressors, flaccid support systems, and social belief systems. Some felt that certain religious beliefs and practices may adversely affect the recovery process. The need for tangible resources and poverty should be addressed, and their basic needs must be satisfied. ${ }^{20-22}$ Housing should offer more than a roof over their heads - it should include access to resources that support recovery. ${ }^{12,21}$ There is also a need to establish community-based mental health care facilities, which reduce the distances travelled by patients with mental illness and their caregivers to seek treatment. ${ }^{23}$ The revised Right of Persons with Disability Act of 2016 in India also specifies $5 \%$ reservation for higher education and $1 \%$ reservation for employment for persons with mental illness. ${ }^{24}$ It is important to give more attention to persons with mental health as they are more prone to other illnesses..$^{22,25}$ Although most patients view their physical health as a high priority, many clinicians consider their primary duty to be management of mental and psychological health. ${ }^{26}$ The subjective physical wellbeing of patients with schizophrenia should be considered by clinicians as an important predictor of relapse, in the same way that psychological aspects are considered. ${ }^{25}$ The same theme of being actively engaged in some meaningful activities and to be with people to reduce the distress has been reported. ${ }^{27,28}$ The impact of illness itself prevents the individual from actively interacting with others or doing work. Negative symptoms of schizophrenia are a predictor of poor outcome..$^{29-32}$ Three factors that predict functional recovery are better social functioning, open employment, and fewer psychiatric symptoms. ${ }^{33}$ The concept of stigma was not an important point in the present study although some caregivers reported about fear of social rejection. Social stigma, discrimination, and perceived self-stigma are significant negative predictors of recovery. ${ }^{18,34,35}$ One barrier in psychiatric rehabilitation is the stigma towards mental patients. Although the general public (especially educated people) accept that these patients should be reintegrated into the community, they still have the problem of the 'not in my back yard' syndrome. ${ }^{36}$

\section{Conclusion}

Treatment adherence, family support, positive attitude towards the illness, and having adequate resources to meet the needs of the patients and their family are interconnected. Thus, giving a pre-treatment counselling to the caregivers and repeating the same content to the patients after regaining insight can be helpful. Our themes are not representative of a full picture of factors affecting recovery from schizophrenia. Perspectives are based on caregivers' experience and can differ from patient to patient and objective evaluation. Cultural differences also exist. Further studies are warranted to confirm the identified themes, to determine the effect of 
each factor, and to compare between different psychiatric conditions or medical illnesses. Professionals should engage everyone in the recovery process to pursue their own goals autonomously with dignity.

\section{Acknowledgement}

We thank family caregivers of patients who participated in this study.

\section{Funding}

The authors received no financial support for the research, authorship, and/or publication of this article.

\section{Declaration}

The authors declared no potential conflicts of interest with respect to the research, authorship and/or publication of this article.

\section{References}

1. Schooler NR, Keith SJ, Severe JB, Matthews SM. Maintenance treatment of schizophrenia: a review of dose reduction and family treatment strategies. Psychiatr Q 1995;66:279-92. Crossref

2. Ganguli HC. Epidemiological findings on prevalence of mental disorders in India. Indian J Psychiatry 2000;42:14-20.

3. McDonell MG, Short RA, Berry CM, Dyck DG. Burden in schizophrenia caregivers: impact of family psychoeducation and awareness of patient suicidality. Fam Process 2003;42:91-103. Crossref

4. Balaji M, Chatterjee S, Brennan B, Rangaswamy T, Thornicroft G, Patel V. Outcomes that matter: a qualitative study with persons with schizophrenia and their primary caregivers in India. Asian J Psychiatr 2012;5:258-65. Crossref

5. Schultz R, Sherwood PR. Physical and mental health effects of family caregiving. Am J Nurs 2008;108(9 Suppl):23-7. Crossref

6. Jose D, Ramachandra, Lalitha K, Gandhi S, Desai G, Nagarajaiah. Consumer perspectives on the concept of recovery in schizophrenia: a systematic review. Asian J Psychiatr 2015;14:13-8. Crossref

7. Griffith TH. Caregiver views on medication treatment for persons with schizophrenia in a cultural context. http://repository.upenn.edu/ edissertations_sp2/21.

8. Spaniol L, Zipple MA. The family recovery process. J Calif Alliance Ment Ill 1994;5:57-9.

9. Arbaiyah. Performance of caregiver in taking care of mental illness patient in family in Aceh Tamilang District, Naggroe Aceh Darussalam Province, Indonesia. Mahidol University; 2008.

10. Chiu MY, Davidson L, Lo WT, Yiu MG, Ho WW. Modelling selfagency among people with schizophrenia: empirical evidence for consumer-based recovery. Psychopathology 2013;46:413-20. Crossref

11. Thirthalli J, Channaveerachari NK, Subbakrishna DK, Cottler LB, Varghese M, Gangadhar BN. Prospective study of duration of untreated psychosis and outcome of never treated patients with schizophrenia in India. Indian J Psychiatry 2011;53:319-23. Crossref

12. Jung SH, Kim WH, Choi HJ, Kang MH, Lee JS, Bae JN, Kim CE. Factors affecting treatment discontinuation and treatment outcome in patients with schizophrenia in Korea: 10-year follow-up study. Psychiatry Investig 2011;8:22-9. Crossref

13. Eaddy M, Grogg A, Locklear J. Assessment of compliance with antipsychotic treatment and resource utilization in a Medicaid population. Clin Ther 2005;27:263-72. Crossref

14. Resnick SG, Fontana A, Lehman AF, Rosenheck RA. An empirical conceptualization of the recovery orientation. Schizophr Res
2005;75:119-28. Crossref

15. Harrow M, Jobe TH. Factors involved in outcome and recovery in schizophrenia patients not on antipsychotic medications: a 15 -year multifollow-up study. J Nerv Ment Dis 2007;195:406-14. Crossref

16. Bobes J, Ciudad A, Álvarez E, San L, Polavieja P, Gilaberte I. Recovery from schizophrenia: results from a 1-year follow-up observational study of patients in symptomatic remission. Schizophr Res 2009;115:58-66. Crossref

17. Torgalsboen AK, Rund BR. Maintenance of recovery from schizophrenia at 20-year follow-up: what happened? Psychiatry 2010;73:70-83. Crossref

18. Tooth B, Kalyanasundaram V, Glover H, Momenzadah S. Factors consumers identify as important to recovery from schizophrenia. Australasian Psychiatry 2003;11(Suppl1):S70-S77. Crossref

19. Webb M, Charbonneau AM, McCann RA, Gayle KR. Struggling and enduring with God, religious support, and recovery from severe mental illness. J Clin Psychol 2011;67:1161-76. Crossref

20. Zanker J. This need not be: mental illness, recovery, and reintegration in resource-poor settings of low-income countries. Doctoral thesis. University of Melbourne; 2008.

21. Browne G, Hemsley M, St John W. Consumer perspectives on recovery: a focus on housing following discharge from hospital. Int $\mathrm{J}$ Ment Health Nurs 2008;17:402-9. Crossref

22. Church K, Costa L, Cheng R, Moffatt K, Mohammed S, Poole J, Reville D, Stackhouse R. Mental Health "Recovery" Study Working Group. Mental Health "Recovery": Users and Refusers. What do Psychiatric Survivors in Toronto Think about Mental Health "recovery"? Wellesley Institute; 2009.

23. Chadda RK. Six decades of community psychiatry in India. Int Psychiatry 2012;9:45-7.

24. The Rights of Persons with Disabilities Act, 2016, Gazette of India (Extra-Ordinary). http://www.disability affairs.gov.in/upload/ uploadfiles/files/RPWD/ACT/2016.pdf.

25. Boyer L, Millier A, Perthame E, Aballea S, Auquier P, Toumi M. Quality of life is predictive of relapse in schizophrenia. BMC Psychiatry 2013;13:15. Crossref

26. Millar H. Management of physical health in schizophrenia: a stepping stone to treatment success. Eur Neuropsychopharmacol 2008;18 Suppl 2:S121-8. Crossref

27. Pernice-Duca F. Family network support and mental health recovery. $\mathrm{J}$ Marital Fam Ther 2010;36:13-27. Crossref

28. Subandi M. The role of family empowerment and family resilience on recovery from psychosis. Gadjah Mada University; 2013.

29. Shahar G, Trower P, Iqbal Z, Birchwood M, Davidson L, Chadwick $P$. The person in recovery from acute and severe psychosis: the role of dependency, self-criticism, and efficacy. Am J Orthopsychiatry 2004;74:480-8. Crossref

30. Landeen J. Recovery in schizophrenia, hope, self-efficacy, and illness intrusiveness. University of Toronto; 2000.

31. Albert N, Bertelsen M, Thorup A, Petersen L, Jeppesen P, Le Quack $\mathrm{P}$, et al. Predictors of recovery from psychosis analyses of clinical and social factors associated with recovery among patients with first-episode psychosis after 5 years. Schizophr Res 2011;125:257-66. Crossref

32. Austin SF, Mors O, Secher RG, HjorthøjCR,Albert N, Bertelsen M, et al. Predictors of recovery in first episode psychosis: the OPUS cohort at 10 year follow-up. Schizophr Res 2013;150:163-8. Crossref

33. Young $\mathrm{KW}$, Ng P, Pan J. Functional recovery of consumers discharged from mental hospital and participating in a communitybased psychosocial programme provided by a non-governmental organisation. East Asian Arch Psychiatry 2014;24:139-47.

34. Klein JM. Change processes in recovering from schizophrenia: a task analysis of personal accounts of recovery. The University of Toledo; 2005.

35. Yanos PT, Roe D, Markus K, Lysaker PH. Pathways between internalized stigma and outcomes related to recovery in schizophrenia spectrum disorders. Psychiatr Serv 2008;59:1437-42. Crossref

36. Mak KY. Psychiatric rehabilitation in the 21st century: a personal view. East Asian Arch Psychiatry 2016;26:3-9. 